\title{
Evidenciação voluntária: fatores explicativos da extensão da informação sobre recursos intangíveis
}

\section{Voluntary disclosure: factors explaining the extent of information on intangible resources}

Clea Beatriz Macagnan

Professora Doutora da Faculdade de Ciências Econômicas da Universidade do Vale do Rio dos Sinos • E-mail: cleabeatriz@hotmail.com

Recebido em 20.10.2008 • Aceito em 12.05.2009 • $3^{a}$ versão aceita em 28.05.2009

\section{RESUMO}

A redução da assimetria de informação contribui para uma melhor distribuição econômica e oportunidades de investimentos. Partindo desse pressuposto, este artigo identifica fatores que influenciam a extensão da evidenciação de informação voluntária, sobre os recursos intangíveis, de empresas listadas na Bolsa Espanhola. Para a análise, utiliza-se a técnica de mínimos quadrados ordinários. Os resultados apontam que fatores como: o tamanho, o setor, o endividamento, o grau de internacionalização, os anos de existência e a diferença entre o preço da ação sobre o valor contábil da empresa explicam a maior extensão da evidenciação de informação de recursos intangíveis. Já, fatores tais como a rentabilidade, o grau de monopólio e o capital flutuante da empresa, explicam a menor extensão da evidenciação dessas informações.

Palavras-chaves: Evidenciação. Recursos intangíveis.

\section{ABSTRACT}

The reduction of information asymmetry leads to a sound economic distribution with better investment opportunities. From this perspective, this paper aims to investigate factors that affect the extent of voluntary information disclosure by companies listed in the Spanish stock exchange. The statistical technique ordinary least squares was used for the sake of analysis. The results suggest that factors like: firm size, economic industry, debt ratio, level of internationalization, age and difference between common stock value and book value explain the greater extent of information disclosure for intangible resources. In turn, factors like profitability, level of monopoly and floating capital of the company explain the lower levels of information disclosure.

Keywords: Disclosure. Intangible resources. 


\section{INTRODUÇÃO}

Esta pesquisa objetiva identificar os fatores que influenciam na extensão da evidenciação ${ }^{1}$ voluntária de informação de empresas listadas no Mercado Contínuo² da Bolsa na Espanha. Estudos sobre evidenciação apontam que a redução da assimetria de informação entre os diretores e os investidores externos contribui, significativamente, para a melhor distribuição das economias e oportunidades de investimento (VERRECCHIA, 1999 e 2001; DYE, 2001; HEALY; PALEPU, 2001; BUKH, 2003). Portanto, este estudo pretende ajudar a entender o comportamento das empresas no que se refere às políticas de evidenciação de informação voluntária.

A informação analisada é representativa de recursos intangíveis ${ }^{3}$, reconhecidos como um diferencial na criação de valor da empre- sa, uma vez que a riqueza e o crescimento na economia seriam determinados por eles (LEV, 2003). Como recursos intangíveis, em grande parte, não recebem tratamento contábil, as empresas evidenciam, voluntariamente, informações sobre eles, diminuindo a assimetria de informação para os investidores. Utiliza-se a técnica de mínimos quadrados ordinários para a análise dos dados.

Na sequência, apresenta-se a revisão da literatura e a formulação das hipóteses da pesquisa. Posteriormente, expõe-se a metodologia utilizada, explicitando-se as variáveis, as técnicas de análise, as fontes de dados utilizadas, assim como a descrição da amostra. A seguir, enunciam-se os resultados da pesquisa. Finaliza-se o estudo com as principais conclusões.

\section{REVISÃO DA LITERATURA E FORMULAÇÃO DAS HIPÓTESES}

A partir da separação entre a propriedade e o controle da organização criam-se as condições da emergência de assimetria de informação entre as partes envolvidas no contrato. O nível de informação é distinto entre o gestor e o investidor externo da empresa, à medida que o segundo é incapaz de observar todas as ações do primeiro, o que impossibilita uma melhor avaliação sobre o valor do negócio por parte do gestor e um frágil conhecimento por parte do investidor externo. A evidência empírica demonstra que a assimetria informativa tem consequências nãodesejadas: valorização ineficiente das ações, elevado custo de capital e benefícios excessivos para quem tem acesso privilegiado à informação (LEV, 2001 e 2003). A evidenciação da informação seria constituída como uma das condições para a redução da assimetria de informação, permitindo uma valorização mais ajustada aos interesses do gestor e do investidor.

Em teoria, distintas motivações poderiam influenciar os gestores a evidenciar ou não informação de forma voluntária. A inserção da empresa no mercado de capitais seria uma das motivações favoráveis à evidenciação. A diversidade de ofertas de ações permite que os investidores escolham entre as possibilidades existentes. Isso levaria os gestores a evidenciarem informações de forma voluntária, objetivando expressar as diferenças da empresa e reduzir a percepção de risco para o investidor. Outra motivação estaria relacionada com a preocupação da direção de explicar as

\footnotetext{
Entende-se evidenciar informação no sentido de representar uma realidade subjacente dos recursos intangíveis da empresa.

2 O Mercado Contínuo é formado pelo primeiro mercado, constituído por três segmentos que atuam com regulação específica, a saber: Novo Mercado, o Segundo Mercado e o Mercado Latibex. No Mercado Continuo da Bolsa de Espanha, fazem-se transações do Novo Mercado e do Mercado Latibex (RIBAS et al., 2003). 0 Novo Mercado caracteriza-se por empresas de alta tecnologia, de ações com significativa volatilidade e crescimento. A empresa que faz parte desse mercado necessita facilitar mais informações que as outras, mas está dispensada do requisito de rentabilidade mínima. Já o Mercado Latibex é composto por empresas da América Latina. Para integrar esse mercado, as empresas latino-americanas devem seguir as normas da Bolsa da Espanha e cumprir os requisitos da União Européia (RIBAS et al., 2003)

3 Emprega-se o termo como recurso imaterial, conhecimento e capital intelectual.
} 
perdas e ganhos da empresa e, assim, manter a sua valorização. Quando a remuneração dos gestores estivesse relacionada ao rendimento das ações da empresa, a evidenciação de informação voluntária seria, então, um modo de explicar o resultado da empresa e justificar sua remuneração aos investidores externos. A capacidade dos gestores de sinalizar ao mercado os diferenciais da empresa, em relação a possíveis ganhos futuros, seria uma motivação positiva para evidenciar informação. A ameaça de litigação seria outra motivação para os gestores aumentarem ou diminuírem a evidenciação. Seja pela possibilidade de o investidor empreender ações legais por evidenciações inadequadas ou intempestivas ou por não evidenciar (ELLIOTT; JACOBSON, 1994; HEALY; PALEPU, 2001).

Uma motivação, que inibiria a evidenciação de informação, estaria relacionada à possibilidade de perda de competitividade da empresa em relação à concorrência. A evidenciação de informação estratégica da empresa possibilitaria à concorrência ações que significariam perda de vantagens competitivas. Também os custos com a sistematização e publicação da informação desestimulariam evidenciação voluntária. Levando-se em conta a revisão da literatura teórica e a empírica, propõe-se um número de hipóteses que inclui as confirmadas em estudos empíricos revisados e novas formulações que figuram como prováveis contribuições desta pesquisa, que se apresenta na sequência.

\subsection{Formulação das Hipóteses}

O tamanho da empresa é uma das causas mais comuns nos estudos que objetivam explicar a extensão da evidenciação de informação. São as grandes empresas que têm maior número de contratos, maior número de projetos, atividades produtivas e comerciais e que necessitam de mais financiamento. Essa realidade gera mais demanda informativa. Quanto maior for a empresa, maior será a pressão dos grupos políticos no sentido de transferir riquezas para a sociedade (WATTS; ZIMMERMAN, 1990; BIRT et al., 2005). Conscientes dessa necessidade, os gestores evidenciam informação, indicando seus recursos com vistas a valorizar a empresa.

H1: Existe uma relação positiva entre o tamanho e a extensão da evidenciação dos recursos intangíveis da empresa.

Estima-se que a rentabilidade seja outra causa explicativa da extensão de evidenciação de informação da empresa. Teoricamente, uma baixa rentabilidade levaria os gestores a evidenciarem informações que dariam sentido aos resultados obtidos pela empresa. Se a empresa não obteve a rentabilidade esperada, os diretores poderão notar fatos que justifiquem os resultados, minimizando a responsabilidade e garantindo a capacidade e remuneração dos gestores (WAGENHOFER, 1990).

H2: Existe uma relação negativa entre a rentabilidade e a extensão da evidenciação dos recursos intangíveis da empresa.

Outra causa que poderia explicar a extensão da evidenciação dos recursos intangíveis é o setor no qual a empresa pertence. Há pouca probabilidade de que os níveis de evidenciação no relatório anual sejam os mesmos em todos os setores da economia (COOKE, 1992; MEEK et al., 1995; WALLACE et al., 1994). A realidade econômica das empresas pode configurar-se de forma diferenciada conforme o setor em que atuam. Seja por suas diferenças de necessidade financeira, por sua imagem pública ou pelo custo de tributação, por exemplo.

H3: Existe uma relação positiva entre o setor a que pertence a empresa e a extensão da evidenciação dos seus recursos intangíveis.

Outra causa que pode explicar a extensão da evidenciação é o grau de endividamento da empresa: quanto maior é o seu endividamento, mais necessária é a redução da assi- 
metria de informação entre os diretores e os acionistas e, por isso, maior será a extensão da evidenciação que justifique a dívida. Também as emissões de obrigações e outros títulos de dívida podem configurar-se de investimentos em novos projetos que se dispõem como uma oportunidade no mercado, significando que uma ampliação de capital poderia representar uma oportunidade de aumentar as ganhos da empresa. Assim sendo, evidenciar intangíveis que justifiquem investimento do capital obtido com a emissão de obrigações e outros títulos reduziria a assimetria informativa, estabelecendo uma confiança na gestão dos recursos da empresa.

H4a: Existe uma relação positiva entre o nível de endividamento e a extensão da evidenciação dos recursos intangíveis da empresa.

H4b: Existe uma relação positiva entre a emissão de obrigações e outros títulos de dívida e a extensão da evidenciação dos recursos intangíveis da empresa.

H4c: Existe uma relação positiva entre a ampliação do capital e a extensão da evidenciação dos recursos intangíveis da empresa.

O pagamento de dividendos pode ser interpretado como um sinal da capacidade de gestão da empresa e ganhos para o investidor, uma vez que indicam saúde econômica e financeira da empresa (SUÁREZ, 2003). À medida que ela amplia a distribuição dos dividendos, estaria sinalizando ao mercado que é fiável e eficaz, reduzindo a necessidade de evidenciação de seus recursos intangíveis. Indicaria que seus diretores trabalham centrados nos interesses dos investidores.

H5: Existe uma relação negativa entre o pagamento de dividendos e a extensão da evidenciação dos recursos intangíveis da empresa.

As empresas caracterizadas por atuar em distintos mercados, em nível internacional, estabelecem maior número de relações contratuais, o que possibilitaria maior número de problemas de seleção adversa. Conscientes dessa realidade, os gestores evidenciariam seus recursos intangíveis sinalizando as diferenças que caracterizam a empresa e para não sofrerem ação intervencionista por parte dos distintos governos, minimizando possíveis custos políticos.

H6: Existe uma relação positiva entre o nível de internacionalização e a extensão da evidenciação dos recursos intangíveis da empresa.

O fluxo de caixa operacional é um indicador muito utilizado por investidores, analistas do mercado financeiro e bancos de investimentos (KOLLER et al., 2005). É um indicador da viabilidade financeira da empresa. Quando se trata de liquidez expressa o autofinanciamento disponível no período ao qual se refere. Mede, portanto, a autonomia de que dispõem os dirigentes para financiar novos projetos de investimento sem acudir ao mercado. Sua variação poderia provocar diferentes interpretações sobre o estado financeiro da empresa. Logo, um baixo valor de fluxo de caixa operacional elevaria a extensão de evidenciação dos recursos intangíveis, indicando as potencialidades da empresa.

H7: Existe uma relação negativa entre o fluxo de caixa operacional e a extensão da evidenciação dos recursos intangíveis da empresa.

Os anos de constituição de uma empresa são identificados como uma causa explicativa da extensão da evidenciação (GALLARDO; CASTILLA, 2004; GIBBINS et al., 1990). As empresas jovens são mais caracterizadas pela incerteza do que as com mais tempo de existência, por isso precisariam prestar mais informações. Enquanto a empresa com mais tempo de existência poderia representar solidez, a empresa com poucos anos, poderia significar maior risco e uma nova oportunidade 
de ganhos acima da média de mercado. Desse modo, as novas empresas necessitariam fornecer informações para que seus recursos intangíveis fossem conhecidos, estabelecendo maior confiança sobre o investimento para o acionista.

H8: Existe uma relação negativa entre a quantidade de anos de constituição e a extensão da evidenciação dos recursos intangíveis da empresa.

Pressupõe-se que, para se justificar ante o governo e a sociedade, a empresa monopolista evidenciará mais informações de que as que não são assim caracterizadas. A evidenciação de informação poderia possibilitar uma redução nos custos políticos por medidas governamentais; tanto para empresas que detenham o monopólio por concessões do Estado como para as que têm sua origem monopolista estabelecida por vantagens competitivas.

H9: Existe uma relação positiva entre grau de monopólio e extensão da evidenciação dos recursos intangíveis da empresa.

O capital flutuante da empresa (free float) indica o nível de ações que são comercializadas no mercado de capitais. Se o percentual do capital flutuante é baixo, denota uma forte concentração de ações nas mãos de um núcleo estável de grupos financeiros que, pela elevada porcentagem de ações que possuem, são membros do Conselho de Administração. Consequentemente, isso poderia levar a empresa a fornecer menos informações para o ambiente público nas reuniões privadas com os acionistas majoritários. Se o percentual do capital flutuante é alto, os gestores demonstrariam seus recursos intangíveis como forma de reduzir custos da agência e de manter a valorização das ações da empresa.

H10: Existe uma relação positiva entre capital flutuante e a extensão da evidenciação dos recursos intangíveis da empresa.
A volatilidade das ações da empresa pode influir na decisão do investidor à medida que ele adote um comportamento mais agressivo ou mais conservador. Supõe-se que, na empresa que apresente maior volatilidade, os gestores evidenciariam mais seus recursos intangíveis com o propósito de manter o mercado financeiro informado, permitindo que o investidor entendesse a variabilidade do valor das ações.

H11: Existe uma relação positiva entre a volatilidade das ações e a extensão da evidenciação dos recursos intangíveis da empresa.

As ações podem ser classificadas segundo a relação entre seu valor contábil e o preço de mercado (FAMA; FRENCH, 1995). Um rateio valor contábil/preço abaixo da média (ou, o que é equivalente, um rateio preço/valor contábil acima da média) corresponde a ações denominadas de crescimento (growth stocks). Um rateio valor contábil/preço acima da média corresponde a ações denominadas de valor (value stocks). A assimetria de informação entre as empresas de alta tecnologia e crescimento é maior que nas empresas consolidadas (RYLANDER et al., 2000). Os diretores da empresa estariam interessados em minimizar possíveis conflitos de interesses com os investidores. Evidenciariam informações no sentido de justificarem que a diferença entre o valor contábil e o valor de mercado da empresa se refere a recursos intangíveis não contabilizados; que não se trata de uma valorização especulativa. Poderse-ia inferir, também, que, se essa diferença de valor corresponde a recursos intangíveis, sua evidenciação poderia significar perda de competitividade.

H12: Existe uma relação positiva entre o preço da ação dividido por seu valor contábil e a extensão da evidenciação dos recursos intangíveis da empresa.

Na sequência, apresenta-se a metodologia utilizada para este estudo. 


\section{METODOLOGIA}

\subsection{Caracterização da amostra} analisada $\mathrm{e}$ fontes utilizadas para a obtenção dos dados

A amostra é composta por 94 empresas listadas no mercado continuo espanhol, representando $83 \%$ da população. Há um equilíbrio quanto à representatividade por setor. O setor manufatureiro é o mais representado, com 28 empresas (30\% do total da amostra), seguido pelo setor indústria básica, com 24 empresas (26\%) e o setor comércio, serviços e transportes, com 23 empresas (24\%). O setor da construção é o menos representado, com 19 empresas (20\%). Não se encontram incluídas na amostra as empresas que atuam no mercado financeiro, como bancos, seguradoras e caixas econômicas. As empresas que compõem a amostra faziam parte do mercado contínuo, todas elas participavam do índice geral da Bolsa de Madrid e do IBEX 35, em 2002.

Para o desenvolvimento desta pesquisa, utilizaram-se dados obtidos no relatório anual, publicado na página da Internet, das empresas que compõem a amostra. Essa fonte é reconhecida como canal oficial de comunicação formal mais usual da empresa (CAMFFERMAN, 1997; GANDIA; ANDRÉS, 2003). "A amplitude da informação contida nos relatórios anuais pode ser o determinante principal da qualidade do processo de tomada de decisões sobre investimentos em particular e da distribuição econômica dos recursos em geral" (KAHL; BELKAOUI, 1981, p. 189).

\subsection{Construção das variáveis dependentes}

As variáveis dependentes, representativas da extensão da evidenciação dos recursos intangíveis, foram construídas com base em uma revisão da literatura teórica e empírica, que identificou o uso de indicadores e índices que medem a extensão da evidenciação. Indicadores e índices são instrumentos utilizados e aceitos para identificar e medir a extensão da evidenciação nas pesquisas empíricas (BOTOSAN, 1997; GARCIA-MECA; MARTÍNEZ, 2004; SVEIBY, 2000b).

A elaboração dos indicadores foi construída mediante uma revisão da literatura, teórica e empírica, sobre indicadores representativos de recursos intangíveis. Posteriormente, eles foram testados em doze relatórios anuais de empresas, considerando os quatro setores representativos da amostra. Esse procedimento permitiu ajustes e a confirmação de 123 indicadores. A título de ilustração, o indicador, denominado rotação da planilha, caracterizase como um recurso intangível que indica a taxa de rotação dos trabalhadores durante o ano (LEV, 2003). Por conseguinte, o indicador rotação da planilha representa a capacidade de gestão dos recursos humanos da empresa e o grau de investimentos em capital humano. Uma rotação baixa interpreta-se como sinal de que a empresa investe na formação de seu pessoal; em caso contrario, indica que a empresa não investe em formação. A rotação da planilha indica o retorno dos investimentos feitos em capacitação de pessoal. A perda com a rotação dos trabalhadores é identificada "se se considera que $71 \%$ das empresas da lista Inc. 500 (um grupo de empresas jovens em rápido crescimento) foram criadas por pessoas que reaplicaram ou modificaram inovações desenvolvidas nas empresas onde trabalharam anteriormente" (LEV, 2003, p. 28). Após, esses indicadores foram utilizados na pesquisa de Macagnan (2005) e submetidos à avaliação de quatro pesquisadores com publicações internacionais sobre o tema, que os validaram e os confirmaram.

Posteriormente, realizou-se uma nova revisão da literatura teórica e empírica sobre categorias de recursos intangíveis. A organização em categorias objetiva facilitar a compreensão desses indicadores, na medida em que reúnem um número relevante de atri- 
butos em um mesmo objeto. Certamente, as categorias são reducionistas, mas permitem estabelecer uma ordenação qualitativa que possibilita o entendimento e a prática instrumental dos intangíveis (GRÖJER, 2001). A revisão da literatura apresentou uma diversidade de categorias. A categoria: recurso humano é a única reconhecida igualmente em todos os estudos revisados. As demais categorias encontradas se diferenciam mais pela denominação do que pelos indicadores que a integram. A título de ilustração, os indicadores que compõem a categoria denominada capital relacional se assemelham aos que integram a estrutura externa. Optou-se por agrupar os recursos intangíveis em cinco categorias básicas, a saber:

1. O capital humano: representa indicadores de recursos intangíveis representativos de valores relacionados à competência e a habilidades técnicas do pessoal contratado pela empresa. Essa categoria é composta por trinta indicadores.

2. O capital estrutural tecnológico: representa valores tecnológicos da empresa. Os investimentos em pesquisa e desenvolvimento, licenças e patentes e a evolução técnica do sistema produtivo, composta por vinte e três indicadores dos recursos e capacidades estruturais da empresa.

3. O capital estrutural organizativo: incorpora indicadores representativos de valores relacionados ao sistema de gestão e toda a atividade técnica e organizativa. Compreende vinte indicadores.
4. O capital relacional do negócio: constitui-se dos valores estabelecidos pela capacidade de interação com o mercado, incluindo todas as relações que a organização estabelece, como: clientes, consumidores, intermediários, fornecedores, sócios, donos e credores. Quarenta e dois indicadores formam essa categoria.

5. O capital relacional social: compõe-se dos valores configurados pela capacidade de interação com a sociedade. Essa categoria é composta por oito indicadores (Figura $1 \mathbf{\nabla}$ ).

Mesmo que essas categorias de intangíveis figurem como distintas, existe uma relação de dependência entre elas e os recursos tangíveis e recursos financeiros da empresa (LEV, 2003; STEWART, 1999). Essas categorias são transformadas em índices, que possibilitam medição da extensão dos respectivos indicadores de recursos intangíveis evidenciados. Para cada indicador, atribui-se o valor de 1, quando é confirmada a evidenciação do respectivo recurso intangível e, em caso contrário, o valor de 0, como nos estudos de Cooke (1989, 1991 e 1992), Wagenhofer (1990), Hossain et al. (1995), García e Monterrey (1993), Raffournier (1995) e Williams (2001) que não utilizaram indicadores ponderados, justificando que todos os indicadores são igualmente importantes. Adotado esse critério de medição da evidenciação dos indicadores de recursos intangíveis, foi realizado o cálculo de seus respectivos índices para todas as empresas que compõem a amostra, utilizandose a seguinte fórmula:

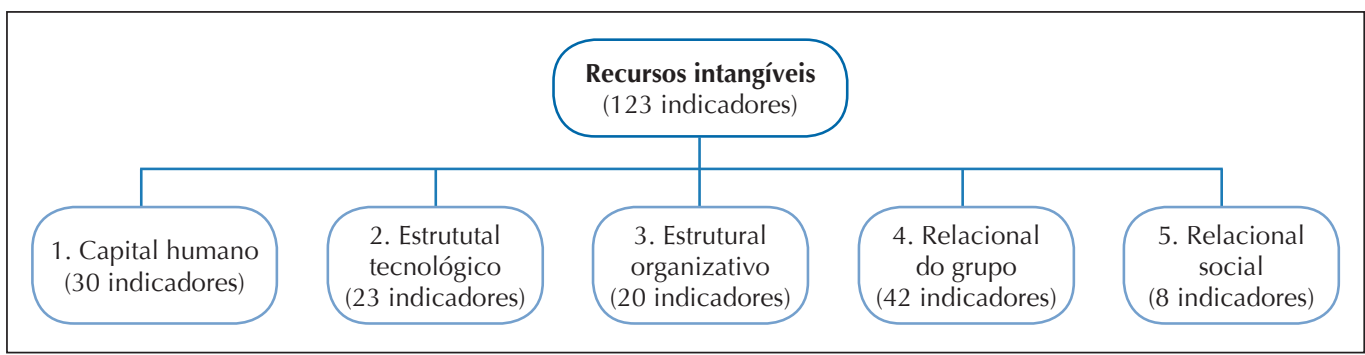

Figura 1 Categorias de indicadores representativos dos recursos intangíveis 


$$
I_{j}=\frac{\sum_{i=1}^{n} x_{i j}}{n_{j}}
$$

Em que o número de indicadores esperados para cada empresa corresponde a $\boldsymbol{n}_{\boldsymbol{j}}$; a empresa é representada pelo índice $\boldsymbol{j}$ e a quantidade de indicadores é expressa por $\boldsymbol{i}$. Quando o indicador $\boldsymbol{X}_{i j}$ é evidenciado, recebe o valor de 1 e 0 se não o for (Quadro $1 \boldsymbol{O})$.

\subsection{Variáveis explicativas}

As variáveis explicativas deste estudo variam conforme as hipóteses formuladas, a saber:

Hipótese tamanho é representada por duas variáveis: (1) valor total das vendas e (2) valor da capitalização, seguindo critério das pesquisas de Cooke (1989, 1992 e 1996), García e Monterrey (1993), Wallace et al. (1994), Raffournier (1995), Meek et al. (1995) e Gómez et al. (2006).

Hipótese rentabilidade é representada por duas variáveis: (1) ROA (rentabilidade do ativo) maior que a média da amostra e (2) crescimento da ROE 2002 - 1997 (rentabilidade dos fundos próprios), seguindo critério das pesquisas de McNally et al. (1982), Richardson e Welker (2001).

\section{Quadro 1 Variáveis DEPENDENTES e} respectivas representações nos modelos

\begin{tabular}{l|c}
\hline Variáveis & Identificação \\
\hline $\begin{array}{l}\text { Extensão evidenciação } \\
\text { do capital humano }\end{array}$ & Rch2 \\
\hline $\begin{array}{l}\text { Extensão evidenciação do } \\
\text { capital estrutural tecnológico }\end{array}$ & Rcet2 \\
\hline $\begin{array}{l}\text { Extensão evidenciação do } \\
\text { capital estrutural organizativo }\end{array}$ & Rceo2 \\
\hline $\begin{array}{l}\text { Extensão evidenciação do } \\
\text { capital relacional do negócio }\end{array}$ & Rcrn2 \\
\hline $\begin{array}{l}\text { Extensão evidenciação } \\
\text { do capital relacional social }\end{array}$ & Rcrs2 \\
\hline
\end{tabular}

Hipótese setor é representada pela variável que reconhece quatro categorias de empresas, baseada na Classificação Nacional de Atividades Econômicas (CNAE), a saber: Indústria Básica: indústria extrativa, siderúrgica, energética e transformadora de metais; Indústria Manufatureira: empresas que fabricam bens, geralmente dirigidos ao consumo; Construção: construção, fabricantes de cimentos e imobiliárias e Comércio, Serviços e Transporte: os segmentos do comércio, serviços em geral e transportes. Variável dicotômica.

Hipótese internacionalização é formada pela variável exportação sobre vendas, construída pelo cálculo: valor das exportações dividido pelo valor das vendas da empresa.

Hipótese anos de constituição da empresa é constituída pela variável que calcula o tempo de formação da empresa até o ano 2002.

Hipótese grau de monopólio é representada pela variável quota de mercado, por identificar um comportamento monopolista, seja por concessões do Estado ou por vantagens competitivas. Seu cálculo é resultado do valor das vendas da empresa dividido pelo valor do total das vendas do setor: $C M=V E / V S$.

Hipótese preço sobre valor contábil das ações é composta por uma variável que resulta do cálculo preço da ação dividido por seu valor contábil.

Hipóteses: endividamento, emissões de obrigações e outros títulos, ampliações de capital, dividendos, fluxo de caixa operacional, capital flutuante e volatilidade são constituídas por variáveis com a mesma denominação (Quadro $2 \bullet$ ).

\subsection{Técnicas estatísticas utilizadas}

A maior parte dos estudos revisados utiliza a técnica de regressão linear múltipla. Um pequeno número de pesquisas, em que a variável dependente se caracteriza como dicotômica, utiliza a técnica de regressão logística, como os estudos de Craswell e Taylor (1992), García e Monterrey (1993), Christopher e Hassan (1995) e Watson et al. (2002). 
Quadro 2 Hipóteses e respectivas variáveis EXPLICATIVAS e representações nos modelos

\begin{tabular}{|c|c|c|}
\hline Hipóteses & Variáveis & Identificação \\
\hline \multirow[t]{2}{*}{ 1. Tamanho } & Vendas & Vendas 2 \\
\hline & Capitalização & Capital2 \\
\hline \multirow[t]{2}{*}{ 2. Rentabilidade } & ROA maior que a média da amostra & Roa2 \\
\hline & Crescimento do ROE - $2002-2007$ & Creo \\
\hline \multirow[t]{4}{*}{ 3. Setor } & Setor indústria básica & Sbasica \\
\hline & Setor indústria manufatureira & Smanof \\
\hline & Setor construção & Sconst \\
\hline & Seror comércio, serviços e transportes & Scst \\
\hline \multirow[t]{3}{*}{ 4. Endividamento } & Endividamento & Endiv2 \\
\hline & Emissões de obrigação e outros títulos & Emis2 \\
\hline & Ampliações de capital & Amplia2 \\
\hline 5. Dividendos & Dividendos & Dividendo2 \\
\hline 6. Internacionalização & Exportações sobre as vendas & ExpVenda2 \\
\hline 7. Fluxo de caixa operacional & Fluxo de caixa operacional & FCaixa2 \\
\hline 8. Anos de constituiçãa & Anos de constituição & Ano \\
\hline 9. Monopólio & Quota de mercado & Cota2 \\
\hline 10. Capital Flutuante & Capital flutuante & CFlutuante2 \\
\hline 11. Volatilidade & Volatilidade & Volátil2 \\
\hline 12. Preço da ação/valor contábil da ação & Preço da ação/valor contábil da ação & Preço2 \\
\hline
\end{tabular}

Optou-se pelo uso da técnica de análise de regressão linear múltipla, segundo mínimos quadrados ordinários, que se ajustam ao objetivo da pesquisa e às características dos dados analisados. Na sequência, apresentam-se os modelos que se diferenciam apenas pela variável dependente.

O modelo 1 propõe-se a identificar as causas que explicam a extensão da evidenciação do capital humano da empresa.

\section{Modelo 1:}

Rch2 $=\beta_{0}+\beta_{1}$ FCaixa $2+\beta_{2}$ Cflutuante $2+$ $\beta_{3}$ Dividendo $2+\beta_{4}$ Volatil $2+\beta_{5}$ Preço $2+\beta_{6}$ Vendas $2+\beta_{7}$ Capital $2+\beta_{8}$ Ano $+\beta_{9}$ Creo + $\beta_{10}$ Roa $2+\beta_{11}$ Scst $+\beta_{12}$ Cota $2+\beta_{13}$ Endiv $2+$ $\beta_{14}$ Emis $2+\beta_{15}$ Amplia $2+\beta_{16}$ ExpVenda $2+\varepsilon$
O modelo 2 apresenta as causas que explicam a extensão da evidenciação do capital estrutural organizacional da empresa.

\section{Modelo 2:}

Rceo $2=\beta_{0}+\beta_{1}$ FCaixa $2+\beta_{2}$ Cflutuante $2+$ $\beta_{3}$ Dividendo $2+\beta_{4}$ Volatil $2+\beta_{5}$ Preço2 $+\beta_{6}$ Vendas $2+\beta_{7}$ Capital $2+\beta_{8}$ Ano $+\beta_{9}$ Creo + $\beta_{10}$ Roa $2+\beta_{11} \operatorname{Scst}+\beta_{12} \operatorname{Cota} 2+\beta_{13}$ Endiv $2+$ $\beta_{14}$ Emis $2+\beta_{15}$ Amplia $2+\beta_{16}$ ExpVenda $2+\varepsilon$

O modelo 3 sugere as causas que explicam a extensão da evidenciação do capital estrutural tecnológico da empresa.

Modelo 3:

Rcet $2=\beta_{0}+\beta_{1}$ FCaixa $2+\beta_{2}$ Cflutuante $2+$ $\beta_{3}$ Dividendo $2+\beta_{4}$ Volatil $2+\beta_{5}$ Preço2 $+\beta_{6}$ Vendas $2+\beta_{7}$ Capital $2+\beta_{8}$ Ano $+\beta_{9}$ Creo + 
$\beta_{10}$ Roa $2+\beta_{11} \operatorname{Scst}+\beta_{12} \operatorname{Cota} 2+\beta_{13}$ Endiv $2+$ $\beta_{14}$ Emis $2+\beta_{15}$ Amplia $2+\beta_{16}$ ExpVenda $2+\varepsilon$

O modelo 4 reconhece as causas que explicam a extensão de evidenciação do capital relacional do negócio.

Modelo 4:

Rcrn2 $=\beta_{0}+\beta_{1}$ FCaixa2 $+\beta_{2}$ Cflutuante $2+$ $\beta_{3}$ Dividendo $2+\beta_{4}$ Volatil2 $+\beta_{5}$ Preço $2+\beta_{6}$ Vendas $2+\beta_{7}$ Capital $+\beta_{8}$ Ano $+\beta_{9}$ Creo + $\beta_{10}$ Roa $2+\beta_{11} \operatorname{Scst}+\beta_{12} \operatorname{Cota} 2+\beta_{13}$ Endiv $2+$ $\beta_{14}$ Emis $2+\beta_{15}$ Amplia $2+\beta_{16}$ ExpVenda $2+\varepsilon$
O modelo 5 explicita as causas que explicam a extensão de evidenciação do capital relacional social.

Modelo 5:

Rcrs2 $=\beta_{0}+\beta_{1}$ FCaixa2 $+\beta_{2}$ Cflutuante $2+$ $\beta_{3}$ Dividendo $2+\beta_{4}$ Volatil2 $+\beta_{5}$ Preço $2+\beta_{6}$ Vendas $2+\beta_{7}$ Capital $2+\beta_{8}$ Ano $+\beta_{9}$ Creo + $\beta_{10}$ Roa $2+\beta_{11}$ Scst $+\beta_{12} \operatorname{Cota} 2+\beta_{13}$ Endiv $2+$ $\beta_{14}$ Emis $2+\beta_{15}$ Amplia $2+\beta_{16}$ ExpVenda $2+\varepsilon$

\section{ANÁLISE DOS RESULTADOS EMPÍRICOS}

\section{Modelo 1}

O resultado do Modelo 1, apresentado na Tabela $1 \boldsymbol{0}$, mostra seis variáveis estatisticamente significativas que explicam a extensão da evidenciação do capital humano, com um coeficiente $\mathrm{R}^{2}$ de $42,41 \%$.

$\mathrm{O}$ modelo 1 indica que, quanto maiores são as vendas e o preço da ação dividido pelo valor contábil, maior será a extensão da evidenciação de recursos intangíveis reconhecidos como capital humano. Demonstra que, quanto maior o crescimento da ROE 2002 1997, a ROA maior que a media da amostra, a quota de mercado e a capitalização menor será a extensão da evidenciação do capital humano da empresa.

\section{Modelo 2}

A Tabela $2 \oslash$ mostra a validação do modelo 2 explicativo da extensão da evidenciação do capital estrutural tecnológico, com um coeficiente de $\mathrm{R}^{2} 33,17 \%$. Outra vez, o logaritmo de vendas e o preço da ação dividido pelo valor contábil estão validados como variáveis que explicam a extensão da evidenciação do capital estrutural tecnológico. Assim, quanto maior forem as vendas e o preço da ação divi-

\section{Tabela 1}

Modelo 1

\begin{tabular}{|c|c|c|c|c|}
\hline \multicolumn{5}{|c|}{ Dependent Variable: Rch2 } \\
\hline \multirow{2}{*}{$\begin{array}{l}\text { Method: Least Squares } \\
\text { Variable }\end{array}$} & \multicolumn{3}{|c|}{ Sample: 194} & \multirow{2}{*}{$\begin{array}{c}\text { Included observations: } \mathbf{9 1} \\
\text { Prob. }\end{array}$} \\
\hline & Coefficient & Std. Error & $t$-Statistic & \\
\hline Logvendas2 & 12.13232 & 1.857648 & 6.531010 & 0.0000 \\
\hline Creo & -5.419342 & 2.299437 & -2.356812 & 0.0208 \\
\hline Roa2 & -4.477515 & 2.409955 & -1.857924 & 0.0667 \\
\hline Cota2 & -0.112861 & 0.057188 & -1.973498 & 0.0517 \\
\hline Capital2 & $-7.36 \mathrm{E}-07$ & $2.36 \mathrm{E}-07$ & -3.120543 & 0.0025 \\
\hline Preço2 & 0.594642 & 0.136858 & 4.344972 & 0.0000 \\
\hline Constante & -43.99954 & 10.00043 & -4.399763 & 0.0000 \\
\hline$R$-squared & 0.424101 & & F-statistic & 10.30981 \\
\hline Adjusted R-squared & 0.382965 & & $\operatorname{Prob}$ (F-statistic) & 0.000000 \\
\hline
\end{tabular}


Tabela 2 Evidenciação do capital estrutural tecnológico

\begin{tabular}{|c|c|c|c|c|}
\hline \multicolumn{5}{|c|}{ Dependent Variable: Rcet2 } \\
\hline Method: Least Squares & \multicolumn{3}{|c|}{ Sample: 194} & \multirow{2}{*}{$\begin{array}{c}\text { Included observations: } 91 \\
\text { Prob. }\end{array}$} \\
\hline Variable & Coefficient & Std. Error & t-Statistic & \\
\hline Logvendas2 & 8.072755 & 2.122033 & 3.804256 & 0.0003 \\
\hline Roa2 & -13.24062 & 3.234478 & -4.093587 & 0.0001 \\
\hline Cota2 & -0.149728 & 0.077105 & -1.941865 & 0.0554 \\
\hline Preço2 & 0.761478 & 0.179812 & 4.234843 & 0.0001 \\
\hline Constante & -11.97546 & 11.69761 & -1.023752 & 0.3088 \\
\hline$R$-squared & 0.331740 & & F-Statistic & 10.67310 \\
\hline Adjusted $R$-squared & 0.300658 & & $\operatorname{Prob}($ F-statistic) & 0.000000 \\
\hline
\end{tabular}

dido sobre o valor contábil da empresa, maior será a extensão da evidenciação do capital estrutural tecnológico. Agora, a rentabilidade do ativo e a quota de mercado são variáveis explicativas que apresentam uma relação negativa com a variável dependente. Isso quer dizer que quanto maiores forem a rentabilidade do ativo e a quota de mercado da empresa, menor será a extensão de evidenciação do seu capital estrutural.

\section{Modelo 3}

A Tabela 30 explicita os resultados do modelo 3 , com o coeficiente $\mathrm{R}^{2} 41,60 \%$, com sete variáveis explicativas, estatisticamente significativas, da evidenciação do capital estrutural organizativo. Logaritmo de vendas, exportações sobre as vendas, preço da ação dividido pelo valor contábil e os anos de constituição da empresa são variáveis explicativas estatisticamente significativas, com uma

Tabela 3 Evidenciação do capital estrutural organizativo

\begin{tabular}{l} 
Dependent Variable: Rceo2 \\
\hline Method: Least Squares
\end{tabular}


relação positiva. Pode-se inferir que, quanto maiores forem as vendas, as exportações sobre as vendas, o preço da ação dividido pelo valor contábil e quanto mais antiga é a empresa, maior será a extensão da evidenciação do capital estrutural organizativo das empresas. E quanto maiores forem a rentabilidade do ativo, a quota de mercado e o capital flutuante da empresa, menor será a extensão da evidenciação do capital estrutural organizativo da empresa.

\section{Modelo 4}

A Tabela 40 apresenta os resultados do modelo de regressão com um $\mathrm{R}^{2}$ de $30,67 \%$, identificando as variáveis: logaritmo de vendas, preço da ação dividido pelo valor contábil e o setor: comércio, serviços e transportes, com resultados estatisticamente significativos. Isso quer dizer que, quanto maior são as cifras de vendas e o preço da ação dividido pelo valor contábil da empresa, maior será a extensão da evidenciação do capital relacional do negócio da empresa. Também manifesta que pertencer ao setor comércio, serviços e transporte, significa que a empresa evidenciará mais seu capital relacional do negócio que as pertencentes aos demais setores.

\section{Modelo 5}

A Tabela 50 mostra as três variáveis, estatisticamente significativas, que compõem o modelo explicativo, com um coeficiente de regressão de $\mathrm{R}^{2} 28,13 \%$. O modelo explicita que quanto maior for a rentabilidade do ativo da empresa, menor será a extensão de evi-

Tabela 4 Evidenciação do capital relacional do negócio

\begin{tabular}{|c|c|c|c|c|}
\hline \multicolumn{5}{|c|}{ Dependent Variable: Rcn2 } \\
\hline \multirow{2}{*}{$\begin{array}{l}\text { Method: Least Squares } \\
\text { Variable }\end{array}$} & \multicolumn{3}{|c|}{ Sample: 194} & \multirow{2}{*}{$\frac{\text { Included observations: } 91}{\text { Prob. }}$} \\
\hline & Coefficient & Std. Error & $t$-Statistic & \\
\hline Logvendas2 & 7.747711 & 1.612951 & 4.803440 & 0.0000 \\
\hline Preço2 & 0.352047 & 0.147579 & 2.385477 & 0.0192 \\
\hline Scst & 5.830474 & 2.920779 & 1.996205 & 0.0490 \\
\hline Constante & -24.05075 & 9.204356 & -2.612975 & 0.0106 \\
\hline$R$-squared & 0.306732 & & F-Statistic & 12.83089 \\
\hline Adjusted $R$-squared & 0.282827 & & Prob(F-statistic) & 0.000001 \\
\hline
\end{tabular}

Tabela 5 Evidenciação do capital relacional social

\begin{tabular}{|c|c|c|c|c|}
\hline \multicolumn{5}{|c|}{ Dependent Variable: Rcrs2 } \\
\hline \multirow{2}{*}{$\begin{array}{l}\text { Method: Least Squares } \\
\text { Variable }\end{array}$} & \multicolumn{3}{|c|}{ Sample: 194} & \multirow{2}{*}{$\frac{\text { Included observations: } 66}{\text { Prob. }}$} \\
\hline & Coefficient & Std. Error & t-Statistic & \\
\hline Roa2 & -15.78348 & 7.504032 & -2.103333 & 0.0395 \\
\hline Ano & 0.374254 & 0.122539 & 3.054151 & 0.0033 \\
\hline Endiv2 & 0.367108 & 0.140440 & 2.613982 & 0.0112 \\
\hline Constante & 21.27482 & 8.785736 & 2.421518 & 0.0184 \\
\hline$R$-squared & 0.281323 & & F-Statistic & 8.089871 \\
\hline Adjusted R-squared & 0.246548 & & Prob(F-statistic) & 0.000125 \\
\hline
\end{tabular}


denciação do capital relacional social. Além disso, o modelo mostra que, quanto maior for o endividamento e os anos de constituição da empresa, maior será a extensão da evidenciação do capital relacional social da empresa.

As variáveis que se mostram insensíveis a respeito da evidenciação de recursos intan- gíveis são: fluxo de caixa operacional (FCaixa2), volatilidade das ações (Volatil2), emissões de obrigações e outros títulos da dívida (Emis2) e ampliações de capital (Amplia2). No próximo capitulo, expõe-se o resultado do contraste das hipóteses propostas como causas explicativas da extensão de evidenciação dos recursos intangíveis.

\section{CONTRASTE DAS HIPÓTESES}

A hipótese sobre tamanho, representada pela capitalização, não pode ser rejeitada como uma causa explicativa da extensão de evidenciação do capital humano. Esse resultado permite inferir que há uma preocupação dos gestores da empresa em minimizar possíveis conflitos de interesses com clientes, investidores e não estariam preocupadas com os concorrentes, com perda de vantagens competitivas por mostrar seus recursos intangíveis.

A hipótese rentabilidade, contrastada pela variável crescimento da rentabilidade do patrimônio (ROE) não é rejeitada, numa relação negativa, como condicionante da extensão de evidenciação do capital humano. $\mathrm{O}$ que permite pensar que os gestores da empresa considerariam desnecessário expor os recursos intangíveis quando sua rentabilidade "falasse" por si, manifestando seu valor e, ao mesmo tempo, evitaria a possibilidade de que a concorrência "atacasse" vantagens competitivas da empresa.

A hipótese sobre setor não é rejeitada. $\mathrm{O}$ setor comércio, serviços e transportes, em relação a outros, é uma causa explicativa da extensão da evidenciação do capital relacional do negócio, com uma relação positiva.

A hipótese endividamento não é rejeitada. Os gestores deram informações para justificar o grau de endividamento, sinalizando possibilidades de ganhos futuros com seus recursos intangíveis. Todavia, a hipótese de que as emissões de obrigações e outros títulos de dívida e de que as ampliações de capital das empresas levariam os gestores a evidenciarem os recursos intangíveis é rejeitada. Não se localizaram pesquisas anteriores que tenham contrastado essas hipóteses.

Não se rechaça a hipótese de que o grau de internacionalização, representado pela variável exportação sobre as vendas, é causa explicativa da extensão de evidenciação do capital relacional organizativo da empresa. As empresas mais centradas em exportações se encontram mais inclinadas a demonstrar seus recursos intangíveis, com o propósito de reduzir conflitos de interesses com governos e sinalizar ao mercado financeiro o valor da empresa.

A hipótese sobre grau de monopólio, contrastada pela variável quota de mercado, não é rejeitada como causa explicativa da extensão da evidenciação dos recursos intangíveis. Pode-se concluir que os gestores adotam o comportamento de demonstrar os recursos intangíveis em maior ou menor medida, dependendo do grau de monopólio que tenha a empresa. Isso não validaria o pressuposto de que os gestores apresentariam mais informações para minimizar possíveis intervenções negativas do governo sobre a empresa. Agora, confirmaria o pressuposto de que a evidenciação de informação daria lugar à perda de vantagens competitivas diante da concorrência.

Não se pode rechaçar essa hipótese sobre a diferença do preço da ação dividido pelo valor contábil da empresa. Isso notifica que quanto maior for a diferença entre o preço sobre o valor contábil da ação, maior será a 
extensão da evidenciação dos recursos intangíveis. Entende-se que há uma preocupação dos gestores em explicar a diferença entre o preço e o valor da ação para os investidores. Também se poderia considerar que as empresas com maior diferença entre o preço e o valor contábil da ação não se sentem ameaçadas pela concorrência por revelar seus recursos intangíveis. Enfatiza-se que essa hipótese não foi contrariada em nenhuma outra pesquisa sobre o tema em estudos revisados.

A hipótese sobre os anos de constituição não é rejeitada, mas com uma relação positiva. Isso quer dizer que, quantos mais anos de existência têm uma empresa, maior é a extensão da evidenciação do capital estrutural organizativo e capital relacional social. Desse modo, não se confirma o pressuposto de que as empresas com menos anos de existência evidenciam mais os recursos intangíveis que as mais antigas. Isso significa que os gestores de empresas mais jovens não entendem que devam dar mais informação sobre o capital estrutural organizativo e o capital relacional social com vistas a uma maior valorização das ações da empresa.

A hipótese sobre capital flutuante não é rejeitada como causa explicativa da extensão da evidenciação do capital estrutural organizativo, mas com relação negativa, indicando que, quanto maior for o capital flutuante, menor será a extensão de evidenciação do capital estrutural organizativo. Isso leva a deduzir que o pressuposto de que os gestores concederam mais informação como forma de minimizar problemas de conflitos de interesse com os investidores não se sustenta. Encontra-se, porém, uma evidência favorável ao pressuposto: os gestores entenderiam que prestar informação poderia significar custo para a empresa, seja pela possibilidade de perda de vantagens competitivas em relação à concorrência, seja pelo custo de sistematizar e publicar informação.

As hipóteses sobre dividendos e sobre fluxo de caixa operacional são rejeitadas como causas explicativas da extensão da evidenciação dos recursos intangíveis. Poder-se-ia inferir que os gestores não entendem que devam prestar mais informações sobre os recursos intangíveis por pagar ou não pagar dividendos ou pela variação do fluxo de caixa operacional. Também, a hipótese de que a volatilidade das ações da empresa tem relação com a extensão da evidenciação dos recursos intangíveis da empresa é rejeitada. Considerando o resultado, infere-se que os gestores não entendem que a redução da assimetria estabeleceria menor volatilidade do valor das ações da empresa.

\section{CONSIDERAÇÕES FINAIS}

Os resultados desta pesquisa permitem depreender que os gestores estão conscientes do déficit na contabilização dos recursos intangíveis e tratam de reduzir a assimetria de informação de forma voluntária para o investidor. Também reconhecem a importância dos recursos intangíveis, pois se não os valorizassem não os evidenciariam.

Com relação às causas explicativas da evidenciação de recursos intangíveis, a confirmação da hipótese Tamanho da Empresa como primeiro fator explicativo da evidenciação dos recursos intangíveis re- afirma os resultados obtidos por $94 \%$ das pesquisas revisadas, sendo o principal fator explicativo. Os setores Internacionalização, Endividamento, Anos de Constituição da Empresa e Diferença Entre o Preço de Seu Valor Contábil se configuram como outros fatores explicativos da evidenciação de recursos intangíveis. Quer dizer que há uma grande probabilidade de que empresas com essas características evidenciem mais seus recursos intangíveis. $\mathrm{O}$ que permite inferir que esses gestores entendem a evidenciação de informações sobre recursos intangíveis 
como uma forma de reduzir a assimetria de informação para o investidor. Assimetria que, nas perspectivas: da teoria de agência, da teoria de custos políticos e na teoria de sinalização, alteraria o custo de capital, contrariando os pressupostos da teoria do custo do proprietário.

No entanto, os gestores de empresas caracterizadas por uma rentabilidade acima da média do mercado, monopolistas e com um maior capital flutuante, tenderiam a prestar menos informações sobre seus recursos intangíveis. Seja por entenderem que a assimetria de informação para o investidor não tem maiores consequências, seja porque estimam que a evidenciação possa significar perda de vantagens competitivas para a empresa, como pressupõe a teoria do custo do proprietário. Já os gestores de empresas que se caracterizam por pagamento de dividendos com maior ou menor fluxo de caixa operacional e com variação na volatilidade das ações, não demonstram preocupação com assimetria de informação para o investidor, no que se refere à evidenciação de seus recursos intangíveis.

Com relação às limitações desta pesquisa, seria importante, em novas pesquisas, ampliar a amostra de empresas em anos, o que possibilitaria identificar a variabilidade do comportamento dos gestores. Igualmente, seria interessante desenvolver este estudo com outra amostra de empresas que cotizem em outros países. Isso permitiria entender as particularidades e o nível de universalidade dos fatores que explicam o comportamento da direção da empresa sobre a evidenciação dos recursos intangíveis. O contraste de outras variáveis seria uma ampliação necessária, posto que o resultado desta pesquisa não identifica todos os fatores explicativos da evidenciação de informação sobre recursos intangíveis. Estudar informações evidenciadas por outros canais de comunicação poderia contribuir para o entendimento das políticas de evidenciação estabelecidas nas empresas. Pode ser que o relatório anual não seja a fonte de informação mais utilizada para a comunicação com o investidor.

\section{Referências}

BIRT, J. et al. Ownership, competition, and financial disclosure. Working Paper, 2005.

BOTOSAN, C. Disclosure level and the cost of equity capital. The Accounting Review, v. 72, p. 323-349, 1997.

BUKH, P. N.; GORMSEN, M. Disclosure of information on intellectual capital in Danish IPO prospectuses?

Working paper, Copenhagen Business, 2003.

CAMFFERMAN, K. Voluntary annual report disclosure

by listed Dutch companies, 1945-1983. New Cork \&

London: Garland Publishing, 1997.

CHRISTOPHER, T.; HASSAN, S. Voluntary disclosure of cash for information: Australian evidence. Working paper, BAA Conference. Bristol, 1995.

COOKE, T. E. Disclosure in the corporate annual reports of Swedish companies. Accounting and Business Research, v. 19, n. 74 , p. $3-124,1989$.

Disclosure in the corporate annual reports of

Swedish companies. Accounting and Business Research, v. 19, p. 113-124, 1991.

. The impact of size, stock market listing and industry type on disclosure in the annual reports of Japanese listed corporations. Accounting and Business Research, v. 22, n. 87, p. 229-237, 1992.

The influence of the keiretsu on Japanese corporate disclosure. Journal of International Financial
Management and Accounting, v. 7, n. 3, p. 191-214, 1996. CRASWELL, A.; TAYLOR, S. Discretionary disclosure of reserves by oil and gas companies: an economic analysis. Journal of Business Finance \& Accounting, v. 19, n. 2, p. 295-308, 1992.

DYE, R. An evaluation of 'essays on disclosure' and the disclosure literature in accounting. Journal of Accounting and Economics, v. 32, p.181-235, 2001.

ELLIOTT, R.; JACOBSON, P. Costs and benefits of business information disclosure. Accounting Horizons, v. 8, n. 4 , p. $80-96,1994$

FAMA, E.; KENNETH R. F. Size and book-to-market factors in earnings and returns. Journal of Finance, v. 50, p. $131-155,1995$.

GALLARDO, D.; CASTILLA, F. La comunicación de información sobre intangibles. Evidencias empíricas que avalan la predisposición del directivo. In: CONGRESSO CONTABILIDADE, 10., 2004, Portugal, Working paper... Portugal, 2004.

GANDÍA, J.; ANDRÉS, T. Transparencia informativa y gobierno corporativo en la era digital. In: CONGRESO AECA, 12., Transparencia Empresarial y Sociedad del Conocimiento, Working paper... 2003.

GARCÍA, M.; MONTERREY, J. La revelación voluntaria en las compañías españolas cotizadas en bolsa. Revista 
Española de Financiación y Contabilidad, n. 74, p. 53-70, 1993.

GIBBINS, M.; RICHARDSON, A.; WATERHOUSE, J. The management of corporate financial disclosure: opportunism, ritualism, policies, and processes. Journal of Accounting Research, v. 28, p. 121-143, 1990. GÓMEZ, J.; IÑIGUEZ, R.; POVEDA, F. Revelación voluntaria de información y características de las sociedades cotizadas en el mercado de capital español.

Revista Española de Financiación y Contabilidad, v. 131, p. 8-32, 2006.

GRÖJER, Jan-E.Intangibles and accounting classifications: in search of a classification strategy. Accounting, Organizations and Society, p. 695-713, 2001. HEALY, P,; PALEPU, K. A review of the voluntary disclosure literature. In: THE 2000 JAE CONFERENCE, Graduate School of Business Harvard University, Working paper... 1999.

Information asymmetry, corporate

disclosure, and the capital markets: a review of the empirical disclosure literature. Journal of Accounting and Economics, Boston, v. 31, p. 405-440, 2001.

HOSSAIN, M.; PERERA, M.; RAHMAN, A.

Voluntary disclosure in the annual reports of New Zealand companies. Journal of International Financial Management \& Accounting, v. 6, p. 69-88, 1995. KAHL, A.; BELKAOUI, A. Bank annual report disclosure adequacy internationally. Accounting and Business Research, p. 189-195, 1981.

KOLLER, T.; GOEDHART, M.; WESSELS, D..Valuation measuring and managing the value of companies. USA: McKinsey Company, 2005.

LEV, B. Intangibles: medición, gestión e información. Barcelona: Deusto, 2001.

Intangible Assets: concepts and measurements

Enciclopedia of Social Measurement, v. 2, 2003.

Disponível em: <www.baruch-lev.com $>$.

MACAGNAN, C. B. Factores explicativos de la revelación de información de activos intangibles de empresas que cotizan en España. Trabajo de Investigación. Universidad Autónoma de Barcelona, 2005. McNALLY, G. M.; ENG, L. H.; HASSELDINE, R. Corporate financial reporting in New Zealand: an analysis of user preferences, corporate characteristics and disclosure practices for discretionary information. Accounting and Business Research, p. 11-20, 1982.
MEEK, G.; ROBERTS, C.; GRAY, S. Factors influencing voluntary annual report disclosures by U.S., U.K. and Continental European multinational corporations. Journal of International Business Studies, p. 555-571, 1995.

RAFFOURNIER, B. The determinants of voluntary financial disclosure by Swiss listed companies. The European Accounting Review, v. 4, n. 2, p. 261-280, 1995. RIBAS, E.; MONTLLOR, J.; TARRAZÓN, M. A. La empresa en el sistema financiero español. 4. ed. Madrid: McGraw Hill, 2003.

RICHARDSON, A.; WELKER, M. Social disclosure, financial disclosure and the cost equity capital.

Accounting, Organizations and Society, v. 26, n. 7-8, p. 597-616, 2001.

RYLANDER, A.; JACOBSEN; K.; ROOS, G. Towards improved information disclosure on intellectual capital. Internacional Journal of Technology Management, v. 20, p. 1-31, 2000 .

STEWART, T. Capital intelectual. A nova riqueza das organizações. Lisboa: Silabo, 1999.

SUÁREZ, A. Decisiones óptimas de inversión y financiación en la empresa. 20. ed. Madrid: Pirámide, 2003.

SVEIBY, K. E. Capital Intelectual. La nueva riqueza de las empresas. Barcelona: Gestión, 2000.

VERRECCHIA, R. Disclosure and cost of capital: a discussion. Journal of Accounting and Economics, v. 26, p. 271-283, 1999.

. Essays on disclosure. Journal of Accounting and Economics, v. 32, p. 97-180, 2001.

WAGENHOFER, A. Voluntary disclosure with a strategic opponent. Journal of.Accounting \& Economics, v. 12, n. 4, p. 341-363, 1990.

WALLACE, O.; NASER, K.; MORA, A. The relationship between the comprehensiveness of corporate annual reports and firm characteristics in Spain. Accounting and Business Research, v. 25, n. 97, p. 41-53, 1994.

WATSON, A.; SHRIVES, P. ; MARSTON, C. Voluntary disclosure of accounting ratios in the UK. British Accounting Review, v. 34, p. 289-313, 2002.

WATTS, R:; ZIMMERMAN, J. Positive accounting theory: a ten year perspective. The Accounting Review, v. 65, n. 1, p. 131-156, 1990.

WILLIAMS, M. Is intellectual performance and disclosure practices related? Journal of Intellectual Capital, v. 2, n. 3, p. 192-203, 2001. 